\title{
MÍDIA IMPRESSA E EDUCAÇÃO CIENTÍFICA: UMA ANÁLISE DAS MARCAS DO FUNCIONAMENTO DISCURSIVO EM TRÊS PUBLICAÇÕES
}

\author{
Sheila Vieira de Camargo Grillo* \\ ENID ABREU DOBRANSZKY* \\ AdRIANA Lia FrisZman LAPLANE**
}

\begin{abstract}
RESUMO: A divulgação de saberes elaborados na esfera científica é constitutiva das funçōes educativas da mídia. Diante disso, este artigo discute as relações e os diferentes valores sociais atribuídos a textos da esfera científica e da jornalística; compara a difusão de saberes na mídia e na escola e identifica as marcas do funcionamento discursivo em textos de divulgação científica na mídia impressa.
\end{abstract}

Palavras-chave: Divulgação científica. Transmissão de conhecimento. Discurso.

Printed Media AND SCIENTIFIC EdUCATION: AN ANALYSIS OF THE MARKS OF THE DISCURSIVE FUNCTIONING IN THREE PUBLICATIONS

ABSTRACT: The diffusion of knowledge elaborated in the scientific sphere is constitutive of the educational functions of the media. This study thus discusses the relationships between texts in the scientific and journalistic spheres and the different values they are given; comparing the diffusion of knowledge by the media and the formal educational system, it identifies the marks of the discursive functioning in texts dealing with the transmission of scientific knowledge.

Key words: Scientific diffusion. Transmission of knowledge. Discourse.

* Doutora em Lingüística pela Universidade de São Paulo (USP) e professora da Faculdade de Letras da mesma Instituição. E-mail: sheilagrillo@uol.com.br

** Doutora em Educação pela Universidade Estadual de Campinas (UNICAMP) e professora do Programa de Mestrado em Educação da Universidade São Francisco (USF). E-mail: enid_abreu@yahoo.com.br

*** Doutora em Educação pela Universidade Estadual de Campinas (UNICAMP) e professora do Programa de Mestrado em Educação da Universidade São Francisco (USF). E-mail: adrifri@fcm.unicamp.br

Cad. Cedes, Campinas, vol. 24, n. 63, p. 215-236, maio/ago. 2004

Disponível em <http://www.cedes.unicamp.br> 
Mídia impressa e educação científica: uma análise...

\section{Introdução}

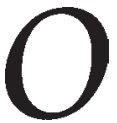

debate que opõe a educação formal e a educação fora da escola não é novo. Os termos desse debate remetem à discussão sobre a possibilidade de a escola cumprir algumas das suas funçôes principalmente a de transmitir conhecimento sistematizado - de modo tal que, ao mesmo tempo, atenda às necessidades e aos interesses dos alunos e aproxime o conhecimento da vida. As críticas à escola centram-se na sua tendência à rotinização, ao enciclopedismo desvinculado das práticas sociais, na tendência a transformar o conhecimento em tarefa escolar e ao conseqüente esvaziamento de sentido que este sofre no decorrer desse processo.

Os discursos de transmissão de conhecimento são lugares privilegiados para observar e analisar as diferenças e semelhanças nas duas modalidades aqui consideradas: a educação formal e a não-formal. A compreensão do modo como os discursos de transmissão de conhecimento funcionam na escola e fora dela pode contribuir para melhor delimitação de ambos os campos e pode vir a ser uma ferramenta que permita aos educadores situar suas práticas, operar no interior desses discursos e, com base nesse conhecimento, estabelecer algum tipo de diálogo com/entre eles.

O presente trabalho analisa alguns exemplos de discursos de transmissão de conhecimento, tomados de livros didáticos e de revistas de divulgação científica. Os livros didáticos exemplificam os discursos didáticos ao passo que as publicações de divulgação científica podem ser caracterizadas como representantes de discursos estritamente informativos e que não manifestariam nenhuma intenção de tornar o outro mais competente em uma área de saber. Esses dois grandes grupos se definem em função das condiçôes de produção, de recepção e de circulação desses discursos.

A análise enfoca, mais especificamente, as peças introdutórias (cartas ao leitor, editoriais, apresentações e prefácios) que abrem as publicaçōes. O exame dos discursos permite discutir a relação editor/ autor-leitor que cada tipo de publicação supõe e torna visíveis os pressupostos e implícitos que conferem a especificidade característica de cada uma dessas publicaçôes. Cabe destacar, também, que existem inúmeras nuanças e diferenças, não apenas entre os diferentes tipos de publicaçôes, mas, também, entre as publicações pertencentes a um 
mesmo grupo. Essas diferenças são relevantes para entender as possibilidades e os limites de cada tipo de discurso.

\section{Discurso didático x divulgação/vulgarização científica}

Tomemos como ponto de partida a distinção entre os discursos socialmente definidos e reconhecidos como didáticos e os de pesquisa científica estabelecida por Beacco \& Moirand (1995): os científicos definem-se por sua função de fazer avançar o estado de conhecimentos de um domínio do saber, ao passo que os didáticos se dirigem a destinatários bem definidos (por nível, por ano etc.), constituindo uma disciplina precisa. Em outras palavras, os discursos didáticos "procuram fazer avançar o estado de conhecimentos no outro, no interior de uma situação ritualizada, regida por um contrato tacitamente aceito pelos interlocutores" (Beacco \& Moirand, 1995, p. 40). Nesse estado de conhecimento, submetido a um processo de rotinização e destinado a sua transmissão numa situação demarcada pela instituição escolar, o discurso pedagógico alça o professor à posição de autoridade do saber - uma autoridade que se apropria do conhecimento e se confunde com o cientista, apagando, conseqüentemente, por não indicar sua posição de mediador, seu modo de apropriação do conhecimento (Orlandi, 1987).

Fora das instituições de formação (científicas e escolares), as formas de transmissão de conhecimentos ocorrem em condições de produção menos facilmente identificáveis. A transmissão do conhecimento pela mídia (jornais, revistas especializadas em divulgação do saber) caracteriza-se pela indeterminação de seus receptores (público leigo), pela não-explicitação de suas condições de produção (diversidade de seus produtores: quem fala, de onde fala, a que grupo pertence), pela variedade dos gêneros do discurso a propósito de um mesmo conhecimento (discurso científico, discurso didático, discurso jornalístico etc.) (Cicurel, Lebre \& Petiot, 1994).

Em ambos os casos - discurso de transmissão pela mídia e discurso pedagógico - configura-se uma situação assimétrica em que um dos interlocutores possui um saber que o outro não tem, quer este saber seja real ou suposto como tal, confirmado ou não por uma posição institucional, profissional ou científica. Para a consideração dos gêneros discursivos produzidos nessas condições, é preciso examiná- 
Mídia impressa e educação científica: uma análise...

los sob as perspectivas formal, pragmática e representacional, ou seja: o estudo da distribuição, da repartição e da densidade dos traços formais de didaticidade; as funções pragmáticas subjacentes aos textos marcados pela didaticidade, isto é, fazer saber, fazer ver, fazer que o outro compreenda, fazer de tal forma que o outro possa se apropriar de saberes novos; e os pré-construídos sobre os quais se apóiam as esquematizações que o locutor elabora, em função da avaliação que ele faz da situação, das representaçōes que ele tem dos destinatários, aquelas que ele dá de si próprio e aquelas que ele tem ou que ele dá do tema.

A partir da análise de textos (carta ao leitor, editorial, apresentação, prefácio) produzidos pelo editor de revistas especializadas em divulgação científica e pelo(s) autor(es) de livros didáticos do ensino médio, apresentamos uma análise comparativa do modo de inscrição da alteridade nessas duas esferas da transmissão de conhecimento.

\section{Dialogismo e transmissão de saberes}

O tratamento da problemática acima esboçada tem recebido contribuições particularmente elucidadoras do campo de estudos da análise do discurso (linha francesa), articulado às noções de dialogismo e de gêneros do discurso, de Bakhtin. Resguardadas as especificidades, as contribuições do círculo de Bakhtin, as teorias da argumentação e a análise do discurso têm em comum a consideração da linguagem no contexto, ou seja, a consideração de aspectos como a dêixis enunciativa (eu/tu, aqui, agora), o quadro institucional, o interdiscurso e o intertexto, a ideologia, os gêneros discursivos.

No seio de um círculo de estudiosos, Bakhtin é o teórico da literatura e da linguagem que, no século XX, retoma os conceitos de enunciação e de gêneros do discurso que haviam sido relegados pela lingüística da época - "A estrutura da enunciação completa é algo cujo estudo a lingüística deixa para outras disciplinas: a retórica e a poética. Ela própria é incapaz de abordar as formas de composição do todo" (1992a, p. 104). A enunciação, entendida como a utilização real e contextualmente determinada da língua, é apreendida em sua natureza dialógica, no sentido de que é uma resposta a discursos anteriormente elaborados e espera/antecipa a compreensão de seus interlocutores: 
Toda enunciação, mesmo na forma imobilizada da escrita, é uma resposta a alguma coisa e é construída como tal. Não passa de um elo da cadeia dos atos de fala. Toda inscrição prolonga aquelas que a precederam, trava uma polêmica com elas, conta com as reaçôes ativas da compreensão, antecipa-as. (Bakhtin, 1992, p. 98)

Authier-Revuz (1998) e Moirand (2000) são dois dos estudiosos que, com base nos estudos bakhtinianos, abordam o discurso da divulgação científica do ponto de vista de sua qualidade de discurso marcado pela textualização de uma dupla alteridade: a presença do discurso científico sob a forma de reformulação e do discurso citado, e as marcas do diálogo com o leitor "leigo". Zamboni (2001, p. 140) contesta essa inserção da divulgação científica entre os discursos de reformulação, ao defender

o discurso da divulgação científica como um trabalho de efetiva formulação de um novo discurso, trabalho exercido por um sujeito enunciador ativo, e não simplesmente assujeitado aos discursos prévios (mas nem por isso senhor absoluto de seu dizer), que agencia, entre os elementos disponíveis na língua, aqueles que melhor respondem ao seu empreendimento enunciativo.

A discordância dá-se em torno da análise da relação entre o discurso científico e o da divulgação científica, ou seja, trata-se do modo de contato entre duas esferas de circulação do saber e da linguagem: a esfera científica e a esfera da mídia (na qual se insere a divulgação científica). Pensamos que o modo de funcionamento desta, apesar de sujeito a regras próprias (a necessidade de vender um produto, a diversidade do público-alvo, a editoração do texto etc.), necessita da legitimidade do discurso científico para a sua eficácia. Em ambos os casos, a teoria bakhtiniana do diálogo com discursos anteriores interdiscurso - e com o leitor-alvo fornece instrumental adequado para a compreensão e a análise dos discursos em questão.

A entrada da enunciação trouxe para o campo de estudos da linguagem consideraçôes de natureza instável, uma vez que a significação é produzida na tensão entre o imobilismo dos sentidos sedimentados na língua e a mudança desses sentidos ocasionada pelos novos contextos de utilização. A linguagem é abordada como acontecimento discursivo, histórica e socialmente determinado. 
Mídia impressa e educação científica: uma análise...

O contexto lingüístico na teoria bakhtiniana compreende duas dimensōes: o contexto mais amplo, constituído pelas relaçóes de produção e pela estrutura sociopolítica, também chamado de infra-estrutura; e o contexto mais imediato, constituído pela situação de comunicação verbal da qual fazem parte as posições assumidas pelos interlocutores, o espaço institucional e geográfico, o momento da enunciação. Esse contexto imediato ritualizado elabora tipos relativamente estáveis de enunciados chamados de gêneros do discurso. Cada setor da atividade humana ou esfera de utilização da língua elabora tipos relativamente estáveis de enunciados do ponto de vista do tema, do estilo e da forma composicional. Os discursos analisados neste artigo procedem de duas esferas de circulação: a esfera midiática e a esfera educacional. Da primeira, serão analisados gêneros de apresentação de revistas de divulgação científica - carta ao leitor e editorial e, da segunda, um prefácio e uma apresentação de livros didáticos de língua portuguesa do ensino médio. Tal como veremos, o gênero escolhido - carta ao leitor, editorial, prefácio, apresentação - não é neutro, mas antes determina o tipo de relação com o público-alvo, ao mesmo tempo que revela as representaçôes dos saberes transmitidos por essas publicações.

A compreensão do diálogo com o interlocutor, tanto na divulgação científica como nos discursos pedagógicos, pode ser enriquecida com as contribuiçôes da retórica nos estudos contemporâneos da argumentação. Um princípio fundamental da argumentação é seu direcionamento para o interlocutor: "É em função de um auditório que qualquer argumentação se desenvolve" (Perelman \& Olbrechts-Tyteca, 1996, p. 6). O auditório é definido como o conjunto daqueles que o orador quer influenciar, sendo que a ação sobre o outro visando a modificar um estado de coisas preexistente é, por um lado, sempre motivada pelas representações que se faz de seus gostos, valores, conhecimentos etc. e, por outro, condicionadora dessas mesmas representações por meio do próprio discurso, isto é, o discurso tanto prevê um interlocutor específico quanto o condiciona a assumir determinados comportamentos. É baseado no tipo de auditório que Perelman e Olbrechts-Tyteca distinguem a persuasão, como a argumentação que toma como alvo um auditório particular, e o convencimento, que busca a adesão de todo ser racional. A relação entre os interlocutores da argumentação é regrada por acordos que se presumem admitidos em 
determinada comunidade. No caso das teorias científicas, Perelman \& Olbrechts-Tyteca (1996) analisam que seus acordos pressupōem um auditório universal e são baseados no conceito de verdade, que diz respeito aos sistemas complexos, transcendentes à experiência, relativos às ligações entre os fatos. Em contrapartida, o discurso científico constitui-se na sua oposição ao senso comum, isto é, ao passo que aquele pressupõe acordos próprios a partidários de uma disciplina particular, fazendo uso de uma linguagem técnica, este é definido como "crenças partilhadas em uma sociedade que as crê partilhadas por todo ser racional" (idem, ibid., p. 112).

$\mathrm{Na}$ sua discussão sobre os âmbitos da argumentação e sobre os acordos presumidos pelos ouvintes, os autores propõem dois pares de oposições, baseados nas relações entre os interlocutores e na representação do objeto do dizer, importantes para os propósitos deste artigo: as oposições propaganda/educação e iniciação/vulgarização. No primeiro par, o estatuto do propagandista é o de granjeador da atenção do seu público, ao passo que o educador usufrui o prestígio de portavoz legítimo dos valores de uma comunidade. O objeto do discurso educacional é apresentado como não sujeito a controvérsias e aproxima-se do discurso publicitário quando se torna vulgarização:

Na educação, seja qual for seu objeto, supõe-se que o discurso do orador, se nem sempre expressa verdades, ou seja, teses aceitas por todos, pelo menos defende valores que não estão, no meio que o delegou, sujeitos a controvérsias. Presume-se que ele usufrui uma confiança tão grande que, ao contrário de qualquer outro, não deve adaptar-se aos seus ouvintes e partir de teses que estes aceitam, mas pode proceder com o auxílio de argumentos a que Aristóteles chama didáticos e que os ouvintes adotam porque "o mestre disse". Ao passo que, numa tentativa de vulgarização, o orador se faz como que o propagandista da especialidade e deve inserir esta no âmbito de um saber comum... (Perelman \& Olbrechts-Tyteca, 1996, p. 59-60)

Para Perelman e Olbrechts-Tyteca, o discurso da vulgarização assenta-se na adaptação ao ouvinte/interlocutor, ao passo que o educacional prescindiria dessa estratégia, uma vez que gozaria de prestígio e legitimidade. No atual cenário da educação brasileira, em que prevalece a competição entre as instituiçôes de ensino privadas e as dificuldades financeiras e pedagógicas da rede pública de ensino fundamental e médio, parece-nos que a lógica comercial das primeiras e 
Mídia impressa e educação científica: uma análise...

a falta de prestígio das segundas levam o discurso educacional a funcionar em uma lógica propagandista de captação do público discente.

Essas reflexôes provindas de algumas teorias da argumentação contribuem significativamente para a problematização e o levantamento de hipóteses sobre os discursos objetos deste artigo: a relação entre os discursos de transmissão do conhecimento (didáticos e informativos) e os discursos-fonte precisa ser considerada à luz das representaçôes dos diferentes tipos de locutores e interlocutores que os diferenciam; entre os discursos de transmissão do conhecimento também ocorrem diferenças na representação dos parceiros do ato de comunicação; os objetos do dizer de discursos explicitamente didáticos e dos discursos de informação adquirem diferentes formas, ou seja, o discurso pedagógico e o discurso de informação parecem se caracterizar por diferentes tipos de argumentos: ao passo que aqueles se apropriam dos argumentos quase-lógicos, estes se definem pelos argumentos baseados na estrutura do real; essas diferenças se manifestam tanto no plano dos conhecimentos compartilhados quanto nos registros empregados, o que coloca a questão da relação entre a linguagem dos domínios especializados e a linguagem corrente, em função das representações dos interlocutores e do suporte material.

\section{A divulgação científica na mídia}

Para a caracterização do funcionamento do discurso de divulgação científica na mídia, foram selecionados trechos da "Carta ao leitor" da revista Superinteressante (São Paulo, Abril, out. 2002) e do "Editorial" da revista Pesquisa FAPESP (São Paulo, FAPESP, out. 2002). A seleção dessas duas publicações fundamentou-se, por um lado, em aspectos comuns - ambas são revistas de divulgação científica, vendidas em bancas de jornal e publicadas no mês de outubro de 2002 e, por outro, em aspectos divergentes - as instituiçôes responsáveis pelas publicações, Editora Abril e Fundação de Amparo à Pesquisa do Estado de São Paulo (FAPESP), ocupam espaços diferentes na sociedade brasileira, o que tem conseqüências no funcionamento discursivo dos textos que iremos analisar.

A revista Superinteressante traz, no início de cada número e ao lado de quadro com informaçôes sobre a equipe editorial da revista e 
da Editora Abril, um texto do gênero "carta ao leitor", assinado pelo diretor de redação. A escolha desse gênero sinaliza a busca de diálogo com o público-alvo, como meio de atingir seus propósitos: a captação do interesse do leitor em função dos temas tratados na edição com vistas à venda da revista.

O texto constrói-se sobre o diálogo eu - diretor de redação -, $t u$ - cada leitor individualmente - e a menção a um ele(s) - repórteres e reportagens:

Eu disse no mês passado que as novidades que marcam nosso aniversário de 15 anos não tinham se encerrado na edição extra de setembro - capa "Diabete" - e na caixa de CDS com a coleção completa da SUPER - dois produtaços que estão nas bancas. E é verdade. Tem muita coisa bacana vindo por aí. Livros, DVDs, um almanaque maravilhoso. Mais a possibilidade de assinar já as 12 edições mensais de Mundo estranho e seis ediçōes especiais da SUPER para 2003. Enfim: prepare o seu coração para tudo que a gente está aprontando para você.

No eixo da intersubjetividade (eu/tu), é produzida a aproximação diretor de redação/cada leitor, por meio da construção de imagens e do apagamento da assimetria repórter (detentor de um saber) e leitor (que busca a informação). Na seqüência, o diretor faz uso de uma série de recursos lingüísticos para construir seu lugar de enunciação: utilização de sufixos e termos próprios a uma linguagem coloquial, produzindo os efeitos de descontração, jovialidade e leveza ("dois produtaços", "coisa bacana”, "embasadíssimos", "aprontando", "primeiríssima qualidade”, "em primeira mão”), simulação da simetria ou mesmo produção de assimetria em benefício do leitor ("Muitas vezes o leitor da SUPER sabe tanto ou mais sobre o assunto em pauta do que os especialistas que ouvimos nas reportagens."), sem contudo abrir mão da seriedade ("uma apuração exemplar que reflete bem o tipo de jornalismo que tentamos fazer na SUPER todo mês: informação e análise de primeiríssima qualidade"). O leitor da revista é inserido no texto, com a utilização de diversas marcas de interlocução ("prepare o seu coração para tudo que a gente está aprontando para você", "Quando digo que você é nosso acionista, meu caro, minha cara, não estou exagerando", "É um tremendo desafio e uma grande satisfação fazer jornalismo para gente como você", "Boa leitura"). Por fim, fora o eixo da intersubjetividade, o texto constrói a legitimidade 
Mídia impressa e educação científica: uma análise...

dos conteúdos veiculados, por meio da exposição e valorização das credenciais da fonte da reportagem ("ouviu ninguém menos que Peter Gay, autor de uma das mais respeitadas biografias de Freud, Fritjof Capra, físico da Universidade Berkeley, um dos fundadores da chamada New Age, e Sophie Freud, a neta do bom velhinho") e da proximidade repórter/leitor ("Para realizar a reportagem que você lê a partir da pág. 42, o editor Rodrigo Cavalcante, um flamenguista nascido em Maceió, homem de letras que também é autor dos vitupérios mais engraçados que ecoam pela redação"). Nesse texto, a transmissão de conhecimento é modulada pela captação e sedução do público leitor, que regula todo o processo: a escolha dos temas, seu enfoque, a postura do repórter e do diretor de redação.

Esse procedimento se enquadra na análise de Barthes (1975) sobre a influência da retórica aristotélica, na qualidade de "arte" de persuadir por meio de estratégias verossímeis, ou seja, daquilo que é opiniāo corrente, nas culturas ditas de massa. ${ }^{1}$ Essa lógica também tem influenciado, a propósito, as práticas escolares que fogem do conflito e buscam a satisfação do aluno como meio de produzir um aparente sucesso educacional.

A revista Pesquisa FAPESP traz, no início de cada número e ao lado de quadro com informações sobre a equipe editorial da revista e da FAPESP, um texto do gênero "editorial". Diferentemente da carta ao leitor, esse gênero, presente em grandes jornais impressos, não vem assinado, pois representa a posição da equipe editorial a respeito dos assuntos tratados naquela edição. A escolha do gênero evidencia a diferença com relação à revista anteriormente analisada: a apresentação e o comentário das reportagens da revista não trazem marcas da relação autor/leitor, legitimando-se pelos critérios científicos e pela relevância das pesquisas descritas nos textos. O "Editorial" inicia-se da seguinte forma:

\section{Surpresas do mundo vegetal}

Os que estão sinceramente preocupados com o futuro do planeta mostram-se indignados com a recusa dos Estados Unidos - o país responsável por um quarto das emissões globais de dióxido de carbono $\left(\mathrm{CO}_{2}\right)$ na atmosfera terrestre - em ratificar o Protocolo de Kyoto, mas perceberam, com alívio, claros sinais, lançados de Johannesburgo em setembro, do crescente isolamento internacional da posição norte-americana. Na dúvi- 
da, contudo, quanto aos bons resultados da diplomacia, os pesquisadores que lidam concretamente com problemas do meio ambiente continuam indo à luta e perseguindo soluções capazes de impedir o desastre anunciado que representaria para a humanidade o aumento descontrolado do gás carbônico no ar que respiramos.

Tal como assinalado, o "Editorial” não apresenta nenhuma marca das pessoas do discurso (eu/tu), construindo-se inteiramente sobre a terceira pessoa, característica dos textos científicos. O segundo parágrafo, que se inicia com "O mundo vegetal revela outra surpresa nesta edição", modula esse recurso - confirmando e estabelecendo-o - pelo uso da terceira pessoa: atribui-se ao mundo vegetal a revelação dos efeitos da planta, e não à atividade de sujeitos cientistas, o que produz o efeito de objetividade do discurso científico.

Os critérios de seleção dos temas das reportagens provêm das duas esferas definidoras da revista: da esfera midiática, a preocupação com assuntos da atualidade e seu impacto social, evidenciados na menção ao "Protocolo de Kyoto", para introduzir a reportagem sobre o jatobá, e ao "significado social" das descobertas sobre a samambaiadas-taperas; e, da esfera científica, os avanços obtidos pelas pesquisas relatadas e sua aplicação tecnológica, presentes na expressão "a par dos resultados científicos" e "novas tecnologias úteis a seu campo de atividades". É o potencial de novidade e sua relevância social que funcionam como índices legitimadores das reportagens, cuja apresentação dispensa a explicitação das credenciais de repórteres e cientistas, autorizados a priori pelo prestígio da FAPESP, na qualidade de órgão de financiamento da pesquisa no Brasil.

Os aspectos acima descritos apontam para o leitor-alvo dessa publicação: familiarizado com assuntos internacionais veiculados pela mídia, conhecedor do prestígio da FAPESP e interessado nas possibilidades de aplicação do conhecimento científico produzido no Brasil. Esse leitor necessita de poucos recursos de sedução para a leitura da revista, além do prestígio que a ciência já goza em nossa sociedade.

A análise da "Carta ao leitor" da Superinteressante e do "Editorial" da Pesquisa FAPESP evidenciam as diferenças entre essas duas publicações. Assim como se observou anteriormente a propósito dos estudos retóricos, a primeira publicação - Superinteressante - desempenha o estatuto do propagandista, isto é, o de granjeador da atenção do seu pú- 
Mídia impressa e educação científica: uma análise...

blico, ao passo que a segunda - Pesquisa FAPESP - usufrui o prestígio de porta-voz legítimo dos valores de uma comunidade, a saber, da comunidade científica brasileira.

\section{O discurso pedagógico no livro didático}

Dois textos foram escolhidos para analisar as particularidades do discurso pedagógico no livro didático. A "Apresentação" do livro Português, cujos autores são Ernani Terra e José De Nicola (São Paulo, Scipione, 2000) e o "Prefácio" do livro Para entender o texto: leitura e redação, de José Luiz Fiorin e Francisco Platão Savioli (São Paulo, Ática, 1999). Assim inicia a "Apresentação":

Esta coleção foi concebida sob o signo da objetividade e da praticidade sem, contudo, abrir mão do rigor da informação e da abrangência do conteúdo. Dessa forma, são apresentados todos os itens que tradicionalmente compõem o conteúdo programático do segundo grau.

Ainda em nome da praticidade, optamos por dividir cada volume em três partes independentes, porém complementares: língua, literatura e redação. Com essa distribuição, cada professor terá maior liberdade para organizar as suas aulas.

A quem ela se dirige? $\mathrm{O}$ interlocutor privilegiado aqui é o professor de língua portuguesa do ensino médio. A objetividade e a praticidade são os valores com os quais se pretende convencer o leitor da importância do livro para a sua prática. Esses valores, entretanto, não são os únicos presentes, já que o texto afirma, também, que não irá abrir mão do rigor da informação e da abrangência do conteúdo. No mesmo parágrafo, o texto remete à tradição para legitimar a sua proposta, alegando que são apresentados todos os itens que tradicionalmente compóem o conteúdo programático do segundo grau. Assim, o texto retira sua legitimidade de argumentos que supóem uma imagem bastante definida do leitor-professor: o livro não é apenas objetivo e prático, como também rigoroso na informação e abrangente no conteúdo, ao ponto de abordar todos os itens que a tradição considera necessários, nos programas vigentes. A imagem de professor que emerge dessas afirmações sugere um usuário cuja principal ação consiste em tomar a decisão de adotar o mencionado livro. Por isso, todos os argumentos procuram convencê-lo da conveniência de tomar essa de- 
cisão. A ação de adotar o livro didático, contudo, transfere, implicitamente, as decisóes subseqüentes, relacionadas ao ensino, para o livro, que assume a função de organizar e apresentar os conteúdos. Esse fato é confirmado pela explicitação de que um certo grau de liberdade é conferido ao professor: o texto explica, no segundo parágrafo, que Ainda em nome da praticidade, optamos por dividir cada volume em três partes independentes, porém complementares: lingua, literatura e redação. Com essa distribuição, cada professor terá maior liberdade para organizar as suas aulas. Os próprios autores, por meio do uso do verbo $o p$ tamos, assumem de forma explícita a função pedagógica, que se estende para especificar e definir o campo onde o professor poderá exercer uma certa liberdade. A idéia de que cada professor terá maior liberdade para organizar as suas aulas mascara, em certa medida, o fato de que a divisão feita pelos autores organiza o conteúdo de acordo com uma visão determinada, sugerindo modos de utilização predefinidos e deixando, portanto, uma margem pequena para a experimentação e para a criatividade. Isso é confirmado pelos parágrafos seguintes, dedicados a explicar as três partes do volume (língua, literatura e redação). Eles constituem a maior parte da "Apresentação" e dão destaque aos critérios que nortearam as escolhas dos autores em termos de conteúdos, textos e pontos de vista.

O "Prefácio" inicia-se com a enunciação dos objetivos que os autores afirmam ser comuns a todos os professores:

\section{Prezado Professor}

Auxiliar o aluno a tornar-se um leitor autônomo e um produtor competente de textos é o compromisso primeiro de nosso ofício.

Todos sabemos, porém, que essa tarefa é difícil. Para contornar essa dificuldade, não têm faltado propostas pedagógicas que, quando não apelam para soluções fáceis, perdem-se em generalidades e conselhos vagos que não fornecem nenhum subsídio para a prática diária do professor e nenhum indicador dos passos que o aluno deve seguir.

O texto convoca e inclui o leitor (professor) ao dizer que esse objetivo compartilhado é o compromisso primeiro de nosso ofício. Isto é reafirmado na frase seguinte, quando o texto continua a sugerir cumplicidade e identificação com um leitor específico ao enunciar: Todos sabemos (...). A seguir, o texto critica as propostas que, quando não apelam para soluçôes fáceis, perdem-se em generalidades e conselhos vagos 
Mídia impressa e educação científica: uma análise...

que não fornecem nenhum subsidio para a prática diária do professor e nenhum indicador dos passos que o aluno deve seguir. Em defesa da própria proposta, o "Prefácio" argumenta que o livro é resultado de estudos $e$ da prática de vários anos em sala de aula, e retoma os objetivos antes enunciados. $\mathrm{O}$ uso de argumentos de autoridade, entretanto, restringe-se aos já mencionados.

À apresentação da organização do livro precedem os pressupostos que orientam a escolha dos conteúdos. São estes os três níveis de conhecimentos necessários, segundo os autores, para a leitura e produção de textos: o sistema lingüístico, abordado pelas gramáticas, o contexto sócio-histórico do texto e os mecanismos de estruturação do significado, a serem abordados no livro.

As lições estão organizadas em quatro partes que incluem: a exposiçãao teórica de um mecanismo de construção de sentido do texto, um texto comentado em que se aplica o mecanismo estudado, um texto acompanhado de um questionário e uma proposta de redação. Ao apresentar cada uma das partes, os autores explicitam seus pressupostos e objetivos. Desse modo, a legitimidade do texto não se assenta apenas em argumentos de autoridade, mas, principalmente, na explicitação das relações entre pressupostos, objetivos e atividades, responsáveis pela eficácia do material apresentado.

Duas questões são, ainda, dignas de nota. Em primeiro lugar, o "Prefácio" reconhece o papel da sensibilidade no desenvolvimento da leitura e produção de textos, mas não a considera um dom e sim uma competência que pode ser aprimorada. Assim, a proposta é apresentada como uma contribuição circunscrita ao espaço determinado da qualidade que se desenvolve. Em segundo lugar, é interessante observar que o papel do professor é destacado de formas diversas ao longo do texto. Inicialmente, quando os autores se identificam como professores, admitindo comunidade de objetivos. Depois, ao enunciar que $O$ comentário sugerido pode ser sempre ampliado pelo professor ou pelos alunos. Como se sabe nenhuma análise é completa e acabada. E, finalmente, quando recomendam que se mostre ao aluno para onde dirigir a atenção e quando solicitam as contribuiçóes dos usuários do livro.

A comparação dos dois textos ora discutidos mostra a diversidade de possibilidades nas relações autor-leitor. Como vimos, os tex- 
tos registram as marcas das imagens que os autores fazem dos leitores, das fontes de legitimidade e dos pressupostos graus de liberdade, dentre outras possíveis de serem analisadas.

\section{Considerações finais}

Análises da relação entre transmissão de saberes na educação e na mídia têm apontado diferenças qualitativas entre ambas, quanto à legitimidade inerente às instituições de ensino e à necessidade de respaldo externo para os veículos de comunicação de massa, na atividade de divulgação científica. Em ambos os casos, porém, parece haver um certo consenso na concepção da instauração de uma relação assimétrica entre educador/jornalista - detentores de um saber - e educandos/público consumidor - destituídos de conhecimento. Essa assimetria é suturada de formas diversas nos textos analisados neste artigo.

$\mathrm{Na}$ análise da "Carta ao leitor" e do "Editorial" dos textos de divulgação científica, mostramos que as publicações mobilizam diferentes recursos retóricos, condicionados pelo quadro institucional e pelo leitor-alvo. A revista Pesquisa FAPESP mobiliza recursos apoiados em argumentos científicos e na relevância social dos temas das reportagens. Já a Superinteressante é modulada pela captação e pela sedução do público leitor, que regula todo o processo de produção das matérias, ao utilizar insistentemente argumentos de autoridade científica sob uma aura de mistificação. A divulgação do saber ganha diferentes feições em razão, na primeira publicação, da busca de legitimação da comunidade científica junto do leitor-alvo e, na segunda, da necessidade de venda de um texto-mercadoria a um público externo à instância de produção do saber, interessado na utilidade da ciência para sua vida e suscetível à reprodução de uma mistificação da atividade científica.

$\mathrm{Na}$ "Apresentação" e no "Prefácio" dos livros didáticos, também constatamos diferenças nas estratégias persuasivas, no que toca à relação com os saberes transmitidos, que buscam, em última instância, o convencimento do professor - lugar do fazer o outro (aluno) saber por meio de estratégias facilitadoras - para a adoção e compra do material. A "Apresentação" do livro Português apóia-se em argumentos de- 
Mídia impressa e educação científica: uma análise...

rivados da utilidade do livro e de autoridade. Essa autoridade advém de uma tradição de ensino capaz de persuadir um docente. O "Prefácio" de Para entender o texto: leitura e redação assenta-se sobre a explicitação das relaçõos entre pressupostos, objetivos e atividades, responsáveis pela eficácia do material apresentado. A menção, aqui, às bases teóricas do trabalho é mínima, pois pressupóe-se que o leitoralvo compartilhe com o autor o estatuto de professor e os fundamentos conceituais da obra e aceite como argumento de autoridade a experiência dos autores. O "Prefácio" concebe o professor como usuário crítico e criativo, capaz de ampliar os comentários e guiar o aluno, e reserva a ele um lugar de destaque que se sustenta, justamente, no background supostamente compartilhado.

Apresentadas as especificidades de discursos articulados às esferas educacional e midiática, chegamos, entretanto, a um conjunto de aspectos que os aproximam. Primeiramente, a finalidade cognitiva, fazer saber, está entrelaçada com a finalidade comercial, fazer comprar (livro didático e revista de divulgação científica), presente em ambos os discursos. Em segundo lugar, a perda da autoridade e da legitimidade das instituições educacionais explica a necessidade de publicização de seu discurso, por meio do uso de estratégias de adaptação ao público discente, aproximando-o do discurso midiático da divulgação científica. Por fim, a utilidade dos materiais didáticos - ligada à facilitação da prática docente - prevalece sobre a pertinência e a legitimidade dos saberes transmitidos e de seus produtores, assim como, na mídia, a apresentação das aplicações práticas das descobertas científicas prevalece sobre a abordagem dos processos de produção do conhecimento.

Vejamos como isso se dá:

\section{Superinteressante}

\section{Um pouco de tudo}

Eu disse no mês passado que as novidades que marcam nosso aniversário de 15 anos não tinham se encerrado na edição extra de setembro - capa "Diabete" - e na caixa de CDS com a coleção completa da SUPER - dois produtaços que estão nas bancas. E é verdade. Tem muita coisa bacana vindo por aí. Livros, DVDs, um almanaque maravilhoso. Mais a possibilidade de assinar já as 12 edições mensais de Mundo estranho e seis edições 
especiais da SUPER para 2003. Enfim: prepare o seu coração para tudo que a gente está aprontando para você.

Quero agradecer às centenas de mensagens que recebi dos assinantes dizendo como foi a experiência de ler duas edições da SUPER em um mês. Quando digo que você é nosso acionista, meu caro, minha cara, não estou exagerando. De verdade, tudo que decidimos fazer na SUPER passa pelo crivo do interesse presumido do leitor. E que leitor! Eu, que venço todas as mensagens que chegam à redação, o que considero uma ferramenta fundamental para a boa gestão editorial, posso falar. Os leitores da SUPER estão entre os mais atilados e instruídos do país. As cartas são sempre articuladas, bem escritas. Os comentários são sempre embasadíssimos. Muitas vezes o leitor da SUPER sabe tanto ou mais sobre o assunto em pauta do que os especialistas que ouvimos nas reportagens. É um tremendo desafio e uma grande satisfação fazer jornalismo para gente como você.

(...)

A reportagem de capa deste mês é uma grande investigação sobre o futuro da psicanálise. Por muito tempo, o divã foi considerado a melhor maneira de atingirmos o autoconhecimento e de tratarmos nossos sofrimentos psíquicos. Isso está mudando. Nunca a teoria psicanalítica foi tão atacada. Como resultado, as pessoas estão cada vez recorrendo menos ao divã em sua busca de felicidade. Procuram a psiquiatria, a psicologia, a espiritualidade. Freud está com os dias contados?

Para realizar a reportagem que você lê a partir da pág. 42, o editor Rodrigo Cavalcante, um flamenguista nascido em Maceió, homem de letras que também é o autor dos vitupérios mais engraçados que ecoam pela redação (xingamentos em sotaque nordestino ficam tão mais divertidos!), ouviu ninguém menos que Peter Gay, autor de uma das mais respeitadas biografias de Freud, Fritjof Capra, físico da Universidade Berkeley, um dos fundadores da chamada New Age, e Sophie Freud, a neta do bom velhinho. Uma apuração exemplar que reflete bem o tipo de jornalismo que tentamos fazer na SUPER todo mês: informação e análise de primeiríssima qualidade, em primeira mão. Boa leitura. (Adriano Silva, Diretor de Redação, Carta ao leitor, outubro de 2002, edição 181)

\section{Pesquisa FAPESP}

\section{Surpresas do mundo vegetal}

Os que estão sinceramente preocupados com o futuro do planeta mostramse indignados com a recusa dos Estados Unidos - o país responsável por um quarto das emissões globais de dióxido de carbono $\left(\mathrm{CO}_{2}\right)$ na atmosfera terres- 
Mídia impressa e educação científica: uma análise...

tre - em ratificar o Protocolo de Kyoto, mas perceberam, com alívio, claros sinais, lançados de Johannesburgo em setembro, do crescente isolamento internacional da posição norte-americana. $\mathrm{Na}$ dúvida, contudo, quanto aos bons resultados da diplomacia, os pesquisadores que lidam concretamente com problemas do meio ambiente continuam indo à luta e perseguindo soluçóes capazes de impedir o desastre anunciado que representaria para a humanidade o aumento descontrolado do gás carbônico no ar que respiramos. Entre as idéias gerais que norteiam essa busca de soluções, uma é particularmente polêmica: transformar as florestas tropicais em aspiradores de dióxido de carbono. Mas, se um dia isso que parece ter a materialidade diáfana de um sonho for possível, um grupo de pesquisadores brasileiros que participam do programa Biota-FAPESP tem um bom candidato a apresentar para o papel de faxineiro do ar: o jatobá. Por que essa grande árvore capaz de alcançar até 20 metros de altura pode ser colocada nessa posição e como os especialistas em fisiologia vegetal chegaram a essa conclusão, é o que mostra Marcos Pivetta na reportagem de capa, a partir da página 26.

O mundo vegetal revela outra surpresa nesta edição, só que, neste caso, desagradável e perigosa. É que a samambaia-das-taperas (Pteridium aquilinum), conhecida também como samambaia-verdadeira e pluma-grande, ingrediente obrigatório de uma receita de frango intensamente consumida na região de Ouro Preto, Minas Gerais, favorece, conforme relata Francisco Bicudo a partir da página 44, a proliferação do papilomavírus humano (HPV), causador de problemas amenos como verrugas, e de outros tão graves quanto cânceres de mama, bexiga e aparelho digestivo. A pesquisa, que, além de apontar esse dado sombrio da samambaia para seus consumidores, sugere também a possibilidade de transmissão do HPV pelo sangue - o que cria um problema até aqui inesperado de saúde pública -, disputou fortemente com o jatobá a capa desta edição, até pelo seu imediato significado social, a par dos resultados científicos.

No fronto da tecnologia vale ressaltar antes de tudo uma novidade que estamos introduzindo a partir desta edição: dentro da seção Linha de Produção, uma subseção de patentes de inovação financiadas e registradas pelo NuPliTeC, o Núcleo de Patenteamento e Licenciamento de Tecnologia da FAPESP. Dessa forma, empresários interessados podem tomar conhecimento e propor o licenciamento de novas tecnologias úteis a seu campo de atividades. Mas entre as várias reportagens que demonstram avanços significativos na pesquisa tecnológica no país, merece destaque especial aquela assinada por Marcos de Oliveira, em que ele explica, a partir da página 62, uma nova técnica que se vale do laser para o diagnóstico precoce do cancro cítrico, doença cujo controle atualmente exige um trabalho extenuante de um batalhão de inspetores e investimentos anuais, por parte dos citricultores paulistas, de quase $\mathrm{R} \$ 100$ milhões. (...) (Editorial, Pesquisa FAPESP, outubro de 2002, n. 80) 


\section{Português}

"Apresentação" do livro Português, cujos autores são Ernani Terra e José De Nicola (São Paulo, Scipione, 2000):

Esta coleção foi concebida sob o signo da objetividade e da praticidade sem, contudo, abrir mão do rigor da informação e da abrangência do conteúdo. Dessa forma, são apresentados todos os itens que tradicionalmente compõem o conteúdo programático do segundo grau.

Ainda em nome da praticidade, optamos por dividir cada volume em três partes independentes, porém complementares: língua, literatura e redação. Com essa distribuição, cada professor terá maior liberdade para organizar as suas aulas.

$\mathrm{Na}$ parte relativa ao estudo de língua, privilegiamos a língua portuguesa culta contemporânea: para tanto, os exemplos das ocorrências gramaticais foram retirados de textos de autores do século XX, de letras de música popular brasileira moderna, de textos jornalísticos e publicitários, de histórias em quadrinhos. Procuramos, assim, aproximar os fatos gramaticais da realidade lingüística dos alunos.

No item relativo à literatura, são apresentados os estilos de época e seus autores mais representativos, desde o Trovadorismo português até a produção contemporânea. No que toca à literatura portuguesa, enfatizamos a Idade Média e o Renascimento, que constituem as raízes históricas da literatura brasileira. A partir do Barroco, realçamos o intercâmbio entre as duas literaturas, com evidente destaque para as produçôes brasileiras (os principais autores e acontecimentos de Portugal recebem espaço na seção Leitura complementar). Na seção Leitura, procuramos apontar alguns caminhos possíveis de interpretação da obra literária, dedicando um comentário para cada texto apresentado.

A parte relativa à redação - um dos pontos fortes desta coleção, acreditamos nós - desempenha o importante papel de promover a síntese e a convergência dos estudos de língua e literatura. Desenvolvemos um intenso trabalho com textos, que servem como material de interpretação e de reflexão para posterior reelaboração. Procuramos realçar conteúdos fundamentais para uma boa produção de textos tanto no que concerne à estruturação gramatical quanto à estilística. Intentamos, assim, aproximar o trabalho de produção de textos das tendências mais atuais dos vestibulares.

Por fim, agradecemos a todos que participaram deste trabalho, seja através dos sempre necessários incentivos, seja através da colaboração direta.

Os Autores. 
Mídia impressa e educação científica: uma análise...

Para entender o texto: leitura e redação

\author{
"Prefácio" do livro de José Luiz Fiorin e Francisco Platão Savioli \\ (São Paulo, Ática, 1999):
}

\title{
Prezado Professor
}

Auxiliar o aluno a tornar-se um leitor autônomo e um produtor competente de textos é o compromisso primeiro de nosso ofício.

Todos sabemos, porém, que essa tarefa é difícil. Para contornar essa dificuldade, não têm faltado propostas pedagógicas que, quando não apelam para soluções fáceis, perdem-se em generalidades e conselhos vagos que não fornecem nenhum subsídio para a prática diária do professor e nenhum indicador dos passos que o aluno deve seguir.

Este livro, resultado de estudos e da prática de vários anos em sala de aula, foi escrito para arriscar uma resposta concreta ao desafio de ensinar o aluno a interpretar e a produzir textos.

Ele surge da crença de que, ao menos no âmbito de nossa realidade social, a escola não pode deixar-se levar pela ilusão de que o aprendizado da leitura e da escrita vá resultar de uma competência a ser espontaneamente adquirida ao longo da experiência escolar. Este livro baseia-se antes no pressuposto de que a explicitação dos mecanismos de produção de sentido do texto contribui decisivamente para melhorar o desempenho do aluno na leitura e na escrita.

Os conhecimentos necessários para ler e produzir textos são de três níveis: conhecimento do sistema lingüístico; conhecimento do contexto sócio-histórico em que o texto foi construído; conhecimento dos mecanismos de estruturação do significado. Este livro ocupa-se dos dois últimos, já que as gramáticas se ocupam do primeiro. Assim, ele procura explicar como um texto se relaciona com outros textos e explicitar os variados processos de construção do significado (estruturas narrativas, temas, expedientes de coesão e de argumentação, recursos expressivos...).

Cada lição procura enfocar um mecanismo de construção do texto. Todas elas, exceto as quatro últimas, que ilustram o trabalho de leitura de diferentes tipos de texto, constam de quatro partes:

a) exposição teórica de um mecanismo de construção do sentido do texto. Procurou-se, o quanto possível, evitar a terminologia especializada. Quando seu uso se tornou indispensável, tomou-se o cuidado de definir os termos e ilustrá-los;

b) um texto comentado em que se aplica o mecanismo estudado na parte teórica. Esse comentário teve sempre a preocupação de explorar a funcionalidade do mecanismo explicitado para fins de compreensão do sig- 
nificado global do texto sob consideração. O comentário sugerido pode ser sempre ampliado pelo professor ou pelos alunos. Como se sabe, nenhuma análise é completa e acabada;

c) um texto, acompanhado de um questionário. Este exercício tem por finalidade levar o aluno, por meio da aplicação dos conceitos apreendidos, a perceber o significado global do texto;

d) uma proposta de redação para estimular o aluno a construir um texto, utilizando o procedimento estudado na lição.

Não ignoramos que a leitura e a produção de texto exigem sensibilidade. Acreditamos, porém, que a sensibilidade não seja um dom inato, mas uma qualidade que se desenvolve. Por outro lado, não basta apenas recomendar ao aluno que leia o texto muitas vezes, é preciso mostrar-lhe para onde dirigir a atenção.

Como todo projeto didático é sempre perfectível, aguardamos as contribuições dos que vierem a adotar este livro.

Os Autores.

Recebido em agosto de 2003 e aprovado em abril de 2004.

\section{Referências bibliográficas}

AUTHIER-REVUZ, J. A encenação da comunicação no discurso de divulgação científica. In: Authier-Revuz, J. Palavras incertas: as nãocoincidências do dizer. Campinas: UNICAMP, 1998. p. 107-131.

AUTHIER-REVUZ, J. Dialogismo e divulgação científica. RUA: revista do Núcleo de Desenvolvimento da Criatividade (NUDeCri) da UNICAMP, Campinas, n. 5, p. 9-16, mar. 1999.

BAKHTIN, M. Os gêneros do discurso. In: BAKHTin, M. Estética da criação verbal. Trad. Maria Ermantina Galvão Gomes Pereira. São Paulo: Martins Fontes, 1992. p. 277-326. (Título original: Estetika Slovesnogo Tvortchestva, 1979).

BAKHTIN, M. Marxismo e filosofia da linguagem. Trad. Michel Lahud e Yara Frateschi Vieira. 6. ed. São Paulo: Hucitec, 1992a. (Título original: Marksizm i filosofija jazyka, 1929).

BARTHES, R. A retórica antiga. In: Cohen, J. et al. Pesquisas em retórica. Petrópolis: Vozes, 1975. p. 147-221. 
Mídia impressa e educação científica: uma análise...

BEACCO, J.C.; MOIRAND, S. Autour des discours de transmission de connaissances. Langages, Paris, n. 117, p. 32-53, mars 1995.

GUIMARÃES, E. (Org.). Produção e circulação do conhecimento: estado, mídia, sociedade. Campinas: Pontes, 2001.

MaingueneAU, D. Análise de textos de comunicação. São Paulo: Cortez, 2001.

MOIRAND, S. Formas discursivas da difusão de saberes na mídia. RUA: revista do Núcleo de Desenvolvimento da Criatividade (NUDECRI) da UNICAMP, Campinas, n. 6, p. 9-24, mar. 2000.

ORLANDI, E. O discurso pedagógico: a circularidade; para quem é o discurso pedagógico. In: Orlandi, E. A linguagem e seu funcionamento: as formas do discurso. 2. ed. Campinas: Pontes, 1987. p. 15-38.

PERELMAN, C.; OLBRECHTS-TYTECA, L. Tratado da argumentação: a nova retórica. Trad. Maria Ermantina Galvão G. Pereira. São Paulo: Martins Fontes, 1996. p. 20-22, 57-60.

ZAMBONI, L.M.S. Cientistas, jornalistas e a divulgação cientifica: subjetividade e heterogeneidade no discurso da divulgação científica. Campinas: Autores Associados, 2001. 